Bangladesh J. Bot. 49(2): 357-365, 2020 (June)

\title{
GENETIC DIVERSITY IN PEARL MILLET RESTORERS BASED ON SEED VIGOUR TRAITS AND SSR MARKERS
}

\author{
Hemender Tanwar*, Shikha Yashveer ${ }^{1}$, Vijay Pal Sangwan, \\ Sushma Sharma, Sonali Sangwan ${ }^{1}$ and Virender Singh Mor \\ Department of Seed Science and Technology, CCS Haryana \\ Agricultural University, Hisar, India
}

Keywords: Genetic diversity, Pearl millet restorers, Seed vigour traits, SSRs

\begin{abstract}
Thirty four pearl millet restorer lines were evaluated on the basis of nine seed vigour traits and molecular analysis was done with 55 SSRs to study the genetic divergence among them. Cluster analysis based on seed vigour parameters revealed the considerable amount of variability and all genotypes were divided into six clusters. Furthermore, a set of 39 SSRs, selected after initial screening of 55, amplified 226 alleles with a mean of 5.84 alleles per locus. The highest polymorphic information content (PIC) value obtained was for PSMP 2084 (0.88) with a range of 0 to 0.88 and average PIC of 0.558 . Neighbor joining tree based on molecular data differentiated all the genotypes into two major groups. The grouping based on both approaches can help breeders to use the studied material in further breeding for improvement of germination potential and early seedling vigour of pearl millet.
\end{abstract}

\section{Introduction}

Pearl millet [Pennisetum glaucum (L.) R. Br.] is typically an arid land crop, it grows commonly in the harsh environments of the semi-arid and arid regions with low precipitation and marginal soils (ICRISAT 2011). This millet provides staple food grain and a source of feed, fodder, fuel and construction material and plays an important role in food security of the hottest and driest drought-prone areas of Africa and the Indian subcontinent where rain-fed agriculture is practiced (Devos et al. 2006). Adaptability to severe environmental conditions has made it a preferred crop in the present era of climate change.

Assessment of genetic diversity and identification of superior genotypes is the first important step in crop improvement. Pearl millet exhibits great diversity both at phenotypic and genotypic levels (Poncet et al. 1998) and therefore needs evaluation of genetic diversity of available inbred lines for hybrid development. In most of the studies, genetic variation among inbred lines or genotypes is being usually assessed by using morphological characters and isozyme markers. There are several studies in literature relating to diversity analysis based on morphological characters (Loumerem et al. 2008, Pucher et al. 2015, Kumari et al. 2016) but the studies related to seed vigour characters are very few (Adebisi et al. 2013a, Jan et al. 2016).

Seed germination and early seedling vigour have prime importance in pearl millet production as this crop is usually grown in rough environments and faces difficulty in establishment in the field. Despite the importance of seed germination and vigour potential, these characters are seldom included in breeding programs of pearl millet. Usually, the restorer lines in the hybrid breeding programs are selected on the basis of their specific morphological characters but the present study has tried to give a glimpse towards a vital character i.e. seed vigour which plays a relevant role in early establishment of pearl millet seedlings in the field. However, the genetic diversity on the

*Author for correspondence: <hemender.sst@gmail.com>. ${ }^{1}$ Department of Molecular Biology, Biotechnology and Bioinformatics, CCS Haryana Agricultural University, Hisar, India. 
basis of morphology and physiology does not provide sufficient information and the results are also environmentally influenced. So, the information at the molecular level is very essential to have a clear picture.

Estimation of genetic diversity at genomic level becomes possible after the development of DNA based marker systems. The development of SSR markers in pearl millet is viewed as a major milestone as it provides an efficient system of analysis for a successful application in analysis of different traits, marker assisted breeding and varietal identification. Moreover, SSRs exhibit codominant inheritance, shows high polymorphism and their detection can be readily automated (Hernandez et al. 2002). Because of these advantages, SSR markers are of extensive use in pearl millet for studying genetic diversity. Hence, an attempt was made to assess the diversity on the basis of seed vigour traits and microsatellite markers in 34 restorer lines and to identify potential pollinators for the development of vigorous hybrids in pearl millet.

\section{Materials and Methods}

The experimental material comprised of 34 pearl millet restorer lines. The seeds were obtained from germplasm collection maintained at Bajra Section, Department of Genetics \& Plant Breeding, CCS Haryana Agricultural University, Hisar. The laboratory and field studies were conducted during 2015 at laboratories and experimental farm of Department of Seed Science and Technology. The experimental farm was situated at CCS Haryana Agricultural University, Hisar with latitude and longitude of $29.1492^{\circ} \mathrm{N}, 75.7217^{\circ} \mathrm{E}$, respectively.

The vigour potential of seeds was assessed by recording nine parameters viz. test weight, standard germination, seedling length, seedling dry weight, vigour index I, vigour index II, accelerated ageing test, electrical conductivity test and seedling establishment, according to the methods described by ISTA (1999) with three replications of each.

Standard germination test was performed using 'Between Paper' method (ISTA 1999). Seedling length $(\mathrm{cm})$ was measured on ten randomly selected normal seedlings taken from standard germination test. These seedlings were dried in hot air oven for $24 \mathrm{hrs}$ at $80 \pm 1^{\circ} \mathrm{C}$ and weighed to obtain average seedling dry weight. The seed vigour indices were calculated by the method suggested by Abdul-Baki and Anderson (1973) which is as follows:

Vigour index-I $=$ Standard germination $(\%) \times$ average seedling length $(\mathrm{cm})$

Vigour index-II $=$ Standard germination $(\%) \times$ average seedling dry weight $(\mathrm{mg})$

Total genomic DNA was extracted from young leaves of pearl millet genotypes using cetyl trimethyl ammonium bromide (CTAB) extraction method following the protocol of SaghaiMaroof et al. (1984) with some minor modifications. PCR was performed in a thermocycler (BioRad) using following conditions: denaturation step of 3 min at $94^{\circ} \mathrm{C}$ followed by 35 cycles each comprised of $1 \mathrm{~min}$ at $94^{\circ} \mathrm{C}, 1 \mathrm{~min}$ at $44-61^{\circ} \mathrm{C}$ (according to each primer) and $1 \mathrm{~min}$ at $72^{\circ} \mathrm{C}$ and final extension step for $10 \mathrm{~min}$ at $72^{\circ} \mathrm{C}$. The amplified fragments were separated on $6.0 \%$ poyacrylamide gel using $0.5 \mathrm{X}$ TBE buffer at $220 \mathrm{~V}$ for $3 \mathrm{hrs}$, stained with ethidium bromide and band sizes estimated using a 20 bp ladder and then recorded under UV in gel documentation system.

Seed vigour data were subjected to non-hierarchical Euclidean cluster analysis using Windostat software V9.3. The cut-off value of Euclidean squared distance for the formation of two major clusters was 2700 (the genotypes merged into a single cluster beyond this level), and then these were further subdivided into smaller clusters at a distance of 260. Molecular data were analyzed for genetic relationships using DARwin-5.0 program (Perrier et al. 2003). A simple matching allele frequency-based similarity matrix was used to construct a tree diagram. Genotypic data generated from SSR markers were further analyzed collectively for all the 34 restorers. 
Allelic richness as determined by total number of alleles, alleles per locus, occurrence of common, most frequent and rare; PIC, gene diversity and heterozygosity were estimated using the PowerMarker V3.0 software (Liu and Muse 2005). Allele classification was done on the basis of method used by Gupta et al. (2015).

\section{Results and Discussion}

All the 34 restorers were grouped in two major clusters at a Euclidean squared distance of 2700 which were finally defined in six clusters at Euclidean squared distance of 260 (Fig. 1). Grouping of 34 genotypes was performed in such a way that genotypes in each cluster had smaller $\mathrm{D}^{2}$ value than those between clusters as shown in Fig. 2. Largest group (cluster 1) consisted of 10 genotypes and cluster 2 was the smallest with 2 genotypes. Cluster 3 (165.84) and cluster 2 (74.92) had the maximum and minimum intra- cluster distances, respectively (Fig. 2). While studying the diversity among the clusters, cluster 2 along with cluster 6 (1419.95) indicated genetically more divergent member genotypes. Comparable level of diversity and genotypic variability was observed for seed vigour parameters by Singh et al. (2003) in durum wheat. The inter-cluster group means for nine characters revealed considerable differences between the

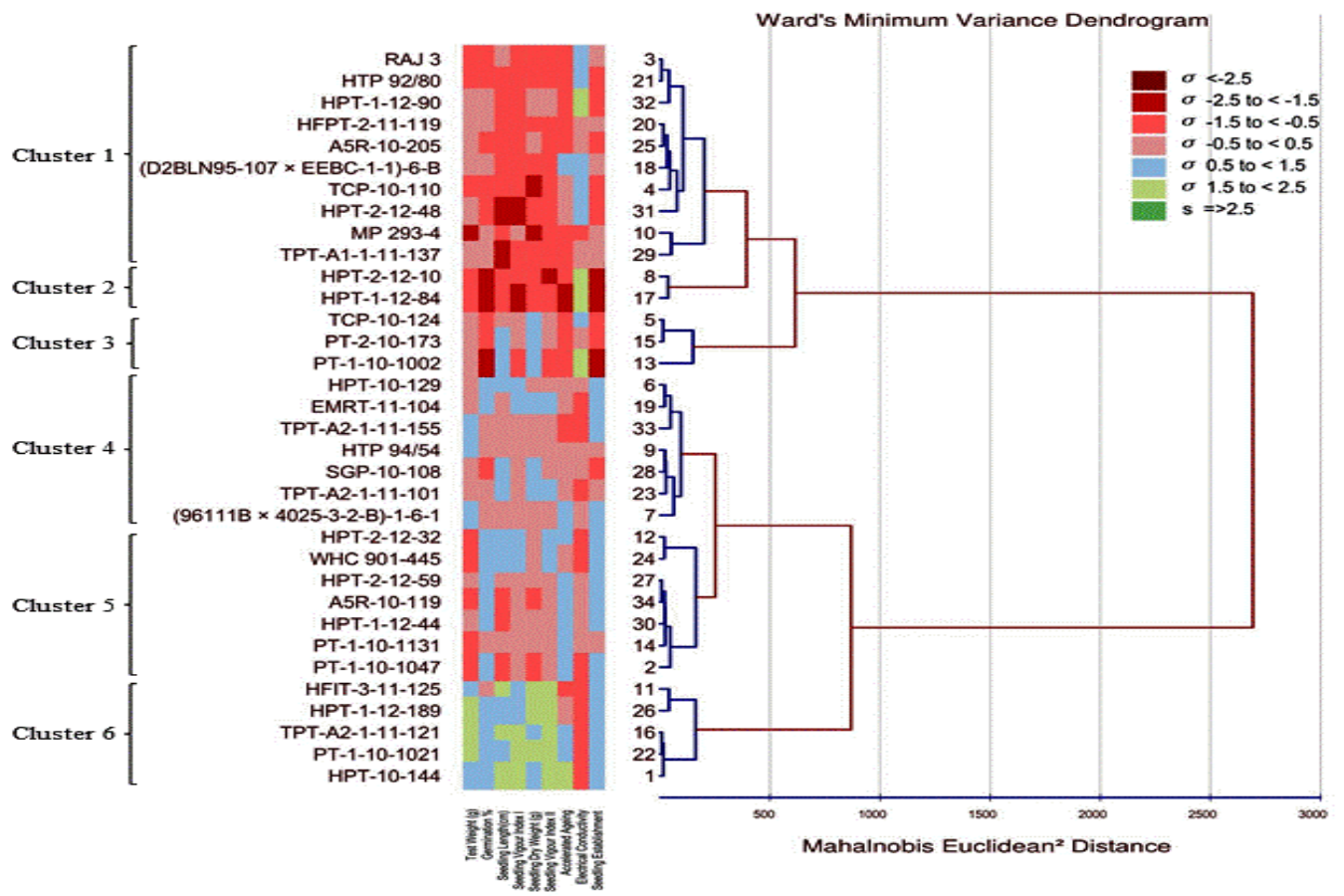

Fig. 1. Dendrogram based on Ward's Minimum Variance method using seed vigour traits.

clusters in respect of cluster means. Cluster wise mean and overall cluster mean for the characters studied are presented in Table 1. Composition of the clusters indicated that cluster 6 is composed of relatively vigorous genotypes because of high mean values of most of the vigour parameters while cluster 2 consisted of low vigour genotypes. Clusters were also found to be distinctive for some traits i.e. standard germination, seedling vigour indices, electrical conductivity etc. Cluster 6 showed highest germination percentage as well as field emergence whereas in cluster 2, highest 
electrical conductivity of seed leachates was observed. These specific associations among the genotypes present in different clusters can be harnessed to improve a significant trait. These findings are in agreement with previous studies on rice genotypes (Adebisi et al. 2013a) and maize inbreds (Adebisi et al. 2013b). Good germination and better seedling vigour are very important in case of pearl millet seed production as pearl millet is usually grown in rain-fed environment. So, this grouping provides a basis for selection of promising lines for future crop improvement programs for traits like initial field emergence and establishment.

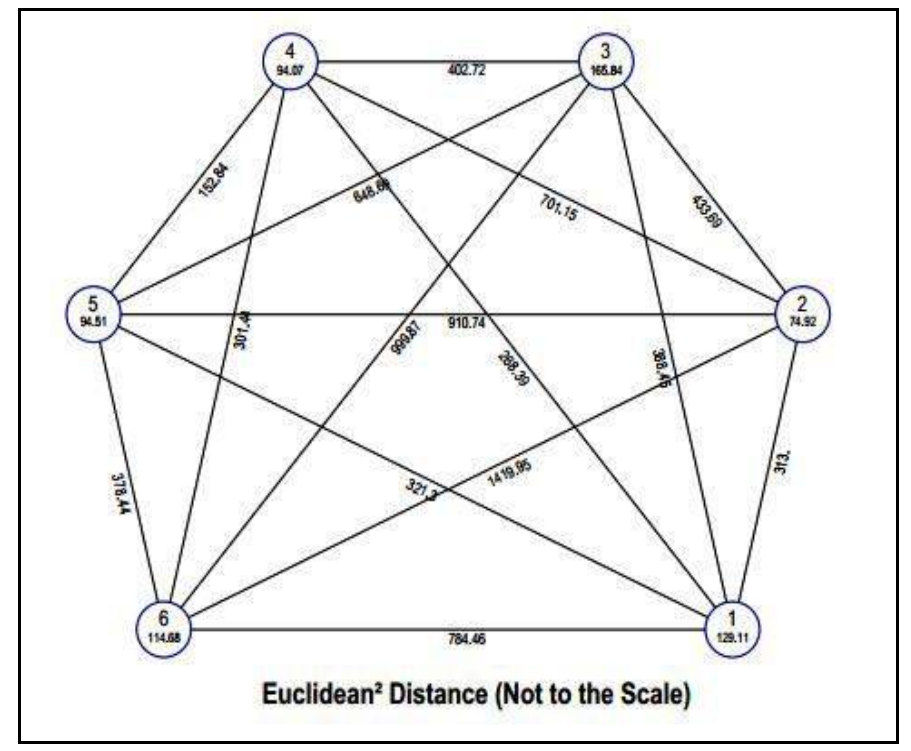

Fig. 2. Star plot showing inter- and intra cluster distance.

Table 1. Mean values of various clusters for different seed vigour parameters.

\begin{tabular}{llllllllll}
\hline Cluster & $\begin{array}{l}\text { TW } \\
(\mathrm{g})\end{array}$ & $\begin{array}{l}\text { SG } \\
(\%)\end{array}$ & $\begin{array}{l}\text { SL } \\
(\mathrm{cm})\end{array}$ & $\begin{array}{l}\text { SDW } \\
(\mathrm{mg})\end{array}$ & VI-I & VI-II & $\begin{array}{l}\text { AA } \\
(\%)\end{array}$ & $\begin{array}{l}\text { EC } \\
(\mathrm{mS} \mathrm{cm} / \mathrm{g})\end{array}$ & $\begin{array}{l}\text { SE } \\
(\%)\end{array}$ \\
\hline 1 & 8.12 & 71.33 & 17.11 & 33.10 & 1220.23 & 2355.23 & 35.63 & 0.188 & 58.33 \\
2 & 7.88 & 50.50 & 18.27 & 32.83 & 923.17 & 1645.83 & 26.83 & 0.253 & 38.83 \\
3 & 9.38 & 60.44 & 23.56 & 50.88 & 1418.78 & 3080.44 & 30.11 & 0.208 & 50.44 \\
4 & 10.16 & 79.19 & 21.73 & 44.95 & 1719.24 & 3546.91 & 44.24 & 0.143 & 69.77 \\
5 & 8.24 & 86.67 & 19.75 & 38.92 & 1715.52 & 3376.67 & 52.52 & 0.128 & 72.57 \\
6 & 12.30 & 91.13 & 24.43 & 55.53 & 2224.80 & 5055.00 & 50.87 & 0.099 & 78.87 \\
\hline
\end{tabular}

TW $=$ Test weight, $\mathrm{SG}=$ Standard germination, $\mathrm{SL}=$ Seedling length, SDW $=$ Seedling dry weight, VI-I = Vigour index I, VI-II = Vigour index II, AA = Accelerated ageing, EC $=$ Electrical conductivity and $\mathrm{SE}=$ Seedling establishment.

Thirty nine primer sets, out of 55 initially screened, amplified total 226 alleles ranging from 1 (XCUMP 001 and XCUMP 0017) to 12 (XCUMP 005) with a mean of 5.79 alleles per locus (Table 2). This value is higher than the values reported in earlier studies, 3 (Singh et al. 2013) and 3.07 (Sumanth et al. 2013) alleles per locus. But the value is much lesser than the value observed by Bashir et al. (2015) and Gupta et al. (2015). However, the value observed in the present study 
Table 2. Amplification results of 39 SSR markers.

\begin{tabular}{|c|c|c|c|c|c|c|c|c|c|}
\hline SSR Loci & SSR motif & $\mathrm{AR}$ & ASR (bp) & RA & $\mathrm{CA}$ & MFA & PIC & GD & $\mathrm{H}$ \\
\hline PSMP 20 & NA & 6 & $155-220$ & 0 & 2 & 2 & 0.65 & 0.70 & 0.21 \\
\hline PSMP 2027 & $(\mathrm{GT})_{31}$ & 9 & $245-380$ & 3 & 2 & 2 & 0.75 & 0.78 & 0.82 \\
\hline PSMP 2059 & $(\mathrm{AC})_{11}$ & 2 & $120-125$ & 0 & 0 & 2 & 0.32 & 0.40 & 0.00 \\
\hline PSMP 2084 & $(\mathrm{AC})_{42}$ & 11 & $220-550$ & 2 & 8 & 0 & 0.88 & 0.89 & 0.93 \\
\hline PSMP 2090 & $(\mathrm{CT})_{12}$ & 6 & $170-230$ & 2 & 3 & 1 & 0.64 & 0.67 & 0.13 \\
\hline PSMP 22 & NA & 4 & $160-210$ & 0 & 2 & 2 & 0.53 & 0.60 & 0.16 \\
\hline PSMP 2201 & $(\mathrm{GT})_{6}$ & 8 & $310-700$ & 1 & 3 & 2 & 0.70 & 0.73 & 0.59 \\
\hline PSMP 2229 & $(\mathrm{GT})_{5}$ & 8 & $230-800$ & 2 & 4 & 2 & 0.81 & 0.83 & 0.63 \\
\hline PSMP 2232 & $(\mathrm{TG})_{8}$ & 7 & $240-380$ & 2 & 2 & 2 & 0.63 & 0.67 & 0.41 \\
\hline PSMP 2237 & $(\mathrm{GT})_{8}$ & 5 & $220-270$ & 2 & 1 & 2 & 0.58 & 0.63 & 0.05 \\
\hline PSMP 2246 & $(\mathrm{TG})_{7}$ & 5 & $260-300$ & 0 & 1 & 3 & 0.70 & 0.75 & 0.13 \\
\hline PSMP 2270 & $(\mathrm{GA})_{26}$ & 3 & $155-175$ & 2 & 0 & 1 & 0.15 & 0.16 & 0.00 \\
\hline PSMP 2271 & $(\mathrm{GA})_{11}$ & 5 & $165-240$ & 1 & 1 & 2 & 0.48 & 0.54 & 0.10 \\
\hline PSMP 2273 & $(\mathrm{GA})_{12}$ & 8 & $160-205$ & 1 & 3 & 2 & 0.76 & 0.79 & 0.19 \\
\hline ICMP 3016 & $(\mathrm{CA}) 17$ & 5 & $400-900$ & 0 & 0 & 3 & 0.74 & 0.77 & 0.74 \\
\hline ICMP 3017 & $(\mathrm{CAG})_{7}$ & 4 & $180-215$ & 0 & 2 & 1 & 0.38 & 0.42 & 0.03 \\
\hline ICMP 3019 & $(\mathrm{CGTA})_{4}$ & 7 & $200-260$ & 0 & 2 & 2 & 0.54 & 0.58 & 0.10 \\
\hline ICMP 3020 & $(\mathrm{CGTG})_{5}$ & 2 & $175-180$ & 0 & 0 & 2 & 0.28 & 0.33 & 0.00 \\
\hline ICMP 3029 & $(\mathrm{GCA})_{6}(\mathrm{GCA})_{5}$ & 4 & $215-260$ & 0 & 2 & 2 & 0.58 & 0.63 & 0.23 \\
\hline ICMP 3050 & $(\mathrm{TA})_{8}$ & 4 & $210-260$ & 0 & 0 & 2 & 0.39 & 0.46 & 0.04 \\
\hline ICMP 3056 & $(\mathrm{TGG})_{5}$ & 1 & 155 & 0 & 0 & 1 & 0.00 & 0.00 & 0.00 \\
\hline ICMP 3088 & $(\mathrm{TCC})_{8}(\mathrm{TCTA})_{4}$ & 8 & $145-320$ & 0 & 5 & 1 & 0.77 & 0.80 & 0.25 \\
\hline XCUMP 001 & $(\mathrm{AG})_{9}$ & 1 & 160 & 0 & 0 & 1 & 0.00 & 0.00 & 0.00 \\
\hline XCUMP 005 & $(\mathrm{CTG})_{9}$ & 12 & $145-250$ & 3 & 3 & 1 & 0.68 & 0.70 & 0.28 \\
\hline XCUMP 006 & $(\text { TATG })_{9}$ & 11 & $150-600$ & 4 & 5 & 1 & 0.82 & 0.83 & 0.89 \\
\hline XCUMP 0016 & $(\mathrm{CT})_{9}$ & 5 & $205-240$ & 0 & 2 & 2 & 0.55 & 0.62 & 0.75 \\
\hline XCUMP 0017 & NA & 1 & 115 & 0 & 0 & 1 & 0.00 & 0.00 & 0.00 \\
\hline XCUMP 0018 & $(\mathrm{GCA})_{7}$ & 9 & $390-900$ & 1 & 6 & 1 & 0.81 & 0.83 & 0.88 \\
\hline СТМ 8 & $(\mathrm{CT})_{8}(\mathrm{CT})_{11}$ & 8 & $245-800$ & 2 & 4 & 2 & 0.82 & 0.84 & 0.78 \\
\hline CTM 10 & $(\mathrm{CT})_{22}$ & 7 & $170-210$ & 0 & 5 & 2 & 0.76 & 0.79 & 0.03 \\
\hline CTM 21 & $(\mathrm{CT})_{24}$ & 4 & $270-290$ & 1 & 1 & 2 & 0.58 & 0.65 & 0.04 \\
\hline СТM 25 & $(\mathrm{CT})_{34}$ & 8 & $240-800$ & 3 & 4 & 1 & 0.75 & 0.78 & 0.53 \\
\hline СТМ 26 & $(\mathrm{CT})_{10}$ & 10 & $240-400$ & 3 & 7 & 0 & 0.85 & 0.87 & 1.00 \\
\hline СТM 27 & $(\mathrm{CT})_{71}$ & 10 & $300-520$ & 2 & 5 & 1 & 0.84 & 0.85 & 0.80 \\
\hline СТМ 55 & $(\mathrm{CT})_{25}$ & 6 & $600-900$ & 1 & 3 & 2 & 0.77 & 0.80 & 0.29 \\
\hline СТM 58 & $(\mathrm{CT})_{24}$ & 1 & 300 & 0 & 0 & 1 & 0.00 & 0.00 & 0.00 \\
\hline PGIRD 46 & $(\mathrm{CTC})_{6}$ & 2 & $80-90$ & 0 & 1 & 1 & 0.10 & 0.11 & 0.00 \\
\hline PGIRD 50 & $(\mathrm{TGT})_{6}$ & 5 & $200-250$ & 0 & 2 & 2 & 0.58 & 0.63 & 0.27 \\
\hline PGIRD 54 & $(\mathrm{GT})_{5}$ & 4 & $110-160$ & 0 & 2 & 2 & 0.61 & 0.66 & 0.39 \\
\hline
\end{tabular}

AR - Allele richness, ASR - Allele size range (bp), RA - Rare alleles ( $\leq 5 \%)$, CA - Common alleles (5 to $\leq 20 \%)$, MFA Most frequent alleles (>20\%), PIC- Polymorphic information content, GD- Gene diversity and H- Heterozygosity. 
is comparable with previous value reported by Nepolean et al. (2012). Usually, SSR markers show a higher degree of polymorphism, which may be attributed to unique replication and slippage mechanism responsible for generation of SSR allelic diversity (Pejic et al. 1998). Moreover, the highest level of polymorphism of many unique alleles can be explained by relatively high rate of mutation in SSR loci (Senior et al. 1998). Previously, similar observations were reported in pearlmillet (Satyavathi et al. 2013) and maize (Russell and Vega 1973). Method of maintenance, residual heterozygosity and mutations are some important factors responsible for such genetic variations (Bogenschutz and Russell 1986). Bantte and Prasanna (2003) also gave some explanations for the occurrence of the double bands or SSR heterozygosity in maize inbred lines due to one or combination of the following reasons: (a) remnant heterozygosity due to early generation nature of the inbred lines, (b) pollen or seed stock contamination, (c) mutation at specific SSR locus, (d) amplification of similar sequences in different genomic regions due to duplications.

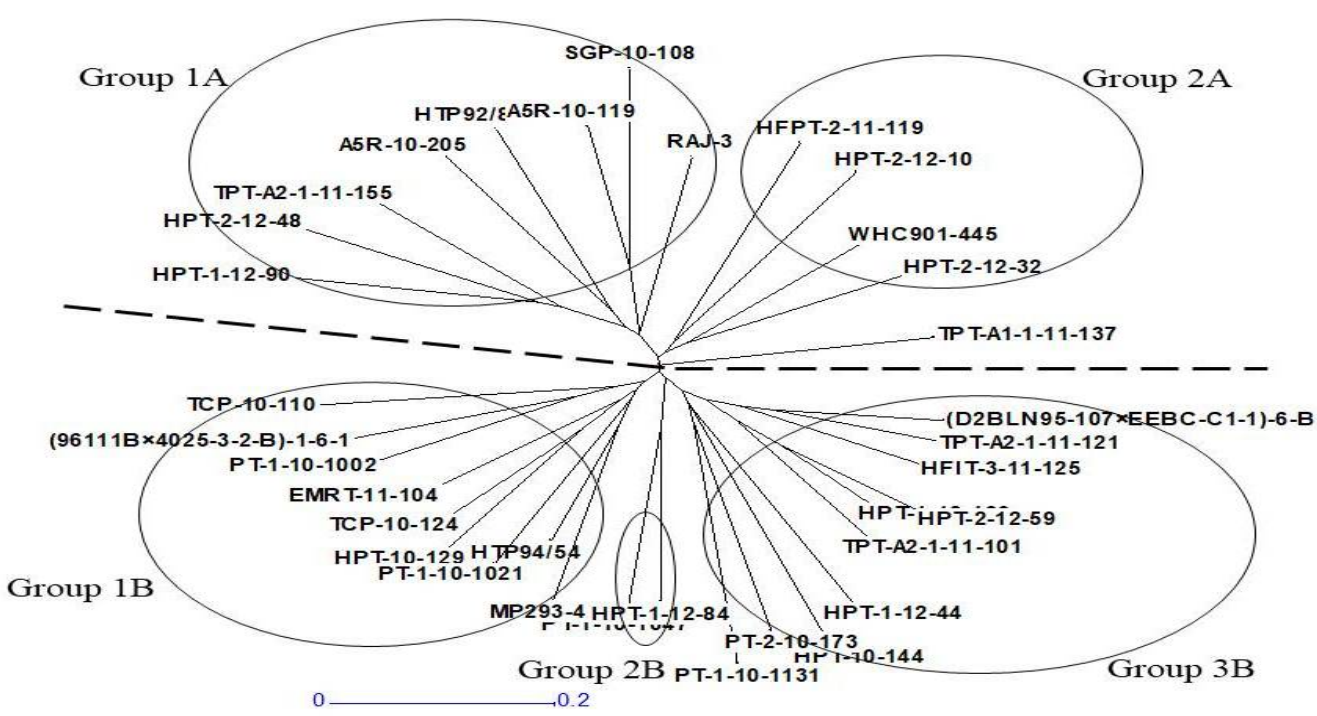

Fig. 3. Unweighted neighbor-joining tree based on a simple matching similarity matrix showing genetic relationship among 34 pearl millet restorers.

PIC values ranged from 0 (XCUMP 001 and XCUMP 0017) to 0.88 (PSMP 2084) with an average of 0.558 (Table 2). This value is near to previously reported value 0.77 (Bashir et al. 2015) and 0.67 (Gupta et al. 2015). But it was higher than that reported by Nepolean et al. (2012), Satyavathi et al. (2013) and Singh et al. (2013). Higher PIC value can be credited to the better resolution of polyacrylamide gel electrophoresis than agarose gel electrophoresis. The range of PIC value showed the significance of locus specific PCR-based microsatellite markers and confirmed that SSR markers are highly elucidative and would be useful in hybrid breeding.

A similarity coefficient matrix derived from simple matching similarity coefficients, was used to calculate the genetic distance among all the genotypes and then the actual cluster analysis was done based on these values by the unweighted pair group method with arithmetic average (UPGMA) for the generation of tree (Fig. 3). In this tree, 33 genotypes were clustered into two major groups while one genotype, namely TPT- $\mathrm{A}_{1}-1-11-137$ remained ungrouped. Group-A consisted of 12 genotypes while Group-B consisted of 21 genotypes which were further 
subdivided into five sub-groups. The subgroup-1A consisted of 8 genotypes whereas subgroup-2A consisted of only 4 genotypes. Subgroup-1B consisted of 9 genotypes. Subgroup-2B was smallest and comprised of only 2 genotypes. Subgroup-3B was largest and consisted of 10 genotypes.

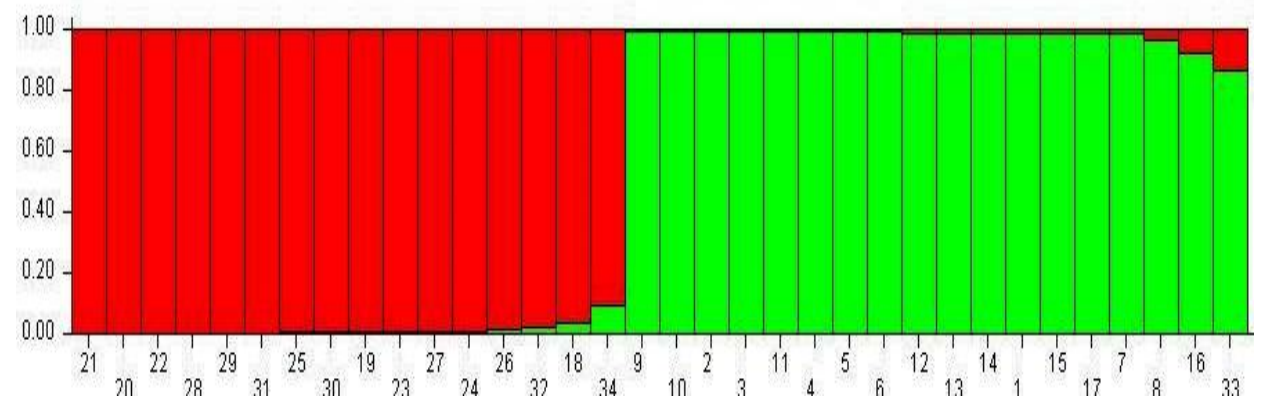

Fig. 4. Graphical representation of population structure.

An attempt was made to derive the relationship between the clustering patterns based on both approaches i.e. seed vigour and molecular. Both of them grouped 34 restorers into two major clusters. Further sub-division revealed the presence of 6 subgroups in seed vigour based dendrogram and 5 subgroups in SSR based tree. Composition of different clusters did not show any clear similar pattern except some minor similarities. For example, two restorers from ICRISAT were grouped in different clusters in both dendrograms and most of the vigorous genotypes from cluster 6 (seed vigour dendrogram) were found to be clustered in group 3B of SSR based tree. Previous studies on pearl millet (Satyavathi et al. 2013) and maize (Mushtaq et al. 2016) also reported similar results that the grouping based on SSR data did not entirely go as per the agro-morphological traits but it could be tracked to the pedigrees to some extent. These types of results might be due to presence of markers which have no linkage to gene loci linked to the trait of interest. However, in some studies, high correlation between molecular data and morphological traits was also reported in pearl millet (Stich et al. 2010) and maize (Gazal et al. 2018).

The model-based STRUCTURE analysis was also carried out to observe the number of populations that may be generated from 34 genotypes using 39 SSR markers. The STRUCTURE simulations were carried out by varying $\mathrm{K}$ from 1 to 10 with 10 run for each $\mathrm{K}$ using all 34 genotypes. $\Delta \mathrm{K}$ showed the highest likelihood at $\mathrm{K}=2$ and topologically meaningful clustering was captured at $\mathrm{K}=2$. In the present study, two populations were obtained with slight mixing in some of the genotypes as represented in Fig. 4. Only 7 genotypes (19.44 \%) among 34 showed some admixtures. Moreover, population structure analysis confirmed the grouping of genotypes, as observed by UPGMA cluster analysis.

Restorer lines are the pollen producing lines used in hybrid breeding of pearl millet. These lines should be vegetatively and reproductively vigorous to produce a good amount of pollen. Effect of early vigor and plant growth on pollen traits was previously reported in wheat (Beri and Anand 1971) and maize (Revilla et al. 1999). Good seed vigour potential and early establishment can produce plants which show better growth especially in the harsh climatic and soil conditions. Usually, restorers are selected on the basis of their specific morphological characters. Here, in the present study, an account of their diversity stance based on seed vigour potential as well as at molecular level is presented. The information depicted in the study can be a convenient source for drafting strategies to improve the use of available germplasm for the aim of better emergence and early growth of pearl millet plants in the current hostile and changing climate. 


\section{References}

Abdul-Baki AA and Anderson JD 1973. Vigor determination in soybean seed by multiple criteria. Crop Sci 13: 630-633.

Adebisi MA, Kehinde TO, Porbeni JBO, Oduwaye OA, Biliaminu K and Akintunde SA 2013b. Seed and seedling vigour in tropical maize inbred lines. Plant Breed. Seed Sci. 67: 87-102.

Adebisi MA, Okelola FS, Ajala MO, Kehinde TO, Daniel TO and Ajani OO 2013a. Evaluation of variations in seed vigour characters of west African rice (Oryza sativa L.) genotypes using multivariate technique. Amer. J. Plant Sci. 4: 356-363.

Bantte K and Prasanna BM 2003. Simple sequence repeat polymorphism in quality protein maize (QPM) lines. Euphytica 129: 337.

Bashir EMA, Ali AM, Mohamed ETI, Melchinger AE, Parzies HK and Haussmann BIG 2015. Genetic diversity of Sudanese pearl millet [Pennisetum glaucum (L.) R. Br.] landraces as revealed by SSR markers, and relationship between genetic and agro-morphological diversity. Genet. Resour. Crop Evol. 62: $579-591$.

Beri SM and Anand SC 1971. Factors affecting pollen shedding capacity in wheat. Euphytica 20: 327-332.

Bogenschutz TG and Russell WA 1986. An evaluation for genetic variation within maize inbred lines maintained by sib-mating and self-pollination. Euphytica 35: 403-412.

Devos KM, Hanna WW and Ozias-Akins P 2006. Pearl millet. In: Genome Mapping and Molecular Breeding in Plants, Kole C (Eds), Volume 1, Cereals and Millets. Springer-Verlag, Berlin, Heidelberg.

Gazal A, Nehvi FA, Lone AA and Dar ZA 2018. Morphological and molecular characterization of maize inbred lines showing variability for drought tolerance. Genet. Mol. Res. 17(2): gmr16039903

Gupta SK, Nepolean T, Sankar SM, Rathore A, Das RR, Rai KN and Hash CT 2015. Patterns of molecular diversity in current and previously developed hybrid parents of pearl millet [Pennisetum glaucum (L.) R. Br.]. Amer. J. Plant Sci. 6: 1697-1712.

Hernandez P, Laurie DA, Martin A and Snape JW 2002. Utility of wheat simple sequence repeat (SSR) markers for genetic analysis of Hordeum chilense and tritordeum. Theor. Appl. Genet. 104: 735-739.

ICRISAT 2011. Production and Productivity Trends of ICRISAT Mandate Crops. Documentation. International Crops Research Institute for the Semi-Arid Tropics, ICRISAT, Patancheru, India.

ISTA 1999. International rules for seed testing. Seed Sci. Technol. 23: 1-334.

Jan N, Lal EP and Kashyap SC 2016. Genetic diversity study of elite rice genotypes for seed and seedling traits. Int. J. Agr. Sci. Res. 6(6): 123-132.

Kumari J, Bag MK, Pandey S, Jha SK, Chauhan SS, Jha GK, Gautam NK and Dutta M 2016. Assessment of phenotypic diversity in pearl millet [Pennisetum glaucum (L.) R. Br.] germplasm of Indian origin and identification of trait-specific germplasm. Crop Pasture Sci. 67: 1223-1234.

Liu K and Muse SV 2005. PowerMarker: Integrated analysis environment for genetic marker data. Bioinformatics 21: 2128-2129.

Loumerem M, Van DP, Reheul D and Behaeghe T 2008. Collection and evaluation of pearl millet (Pennisetum glaucum) germplasm from the arid regions of Tunisia. Genet. Resour. Crop Evol. 55: 1017-1028.

Mushtaq M, Bhat MA, Bhat JA, Mukhtar S and Shah AA 2016. Comparative analysis of genetic diversity of maize inbred lines from Kashmir valley using agro-morphological and SSR markers. SABRAO J. Breed. Genet. 48(4): 518-527.

Nepolean T, Gupta SK, Dwivedi SL, Bhattacharjee R, Rai KN and Hash CT 2012. Genetic Diversity in maintainer and restorer lines of pearl millet. Crop Sci. 52: 2555-2563.

Pejic I, Ajmone-Marsan P, Morgante M, Kozumplick V, Castiglioni P, Taramino G and Motto M 1998. Comparative analysis of genetic similarity among maize inbred lines detected by RFLPs, RAPDs, SSRs and AFLPs. Theor. Appl. Genet. 97: 1248-1255.

Perrier X, Flori A and Bonnot F 2003. Data Analysis Methods. In: Genetic Diversity of Cultivated Tropical Plants, Hamon P, Seguin M, Perrier X and Glaszmann JC (Eds), pp. 43-76, Enfield: Science Publishers. 
Poncet V, Lamy F, Enjalbert J, Joly H, Sarr A and Robert T 1998. Genetic analysis of the domestication syndrome in pearl millet (Pennisetum glaucum L. Poaceae): inheritance of the major characters. Heredity 81: 648-658.

Pucher A, Sy O, Angarawai II, Gondah J, Zangre R, Ouedraogo M, Sanogo MD, Boureima S, Hash CT and Haussmann BIG 2015. Agro-morphological characterization of west and central African pearl millet accessions. Crop Sci. 55: 737-748.

Revilla P, Butrón A, Malvar RA and Ordás RA 1999. Relationship among kernel weight, early vigor, and growth in maize. Crop Sci. 39: 654-658.

Russell WA and Vega UA 1973. Genetic stability of quantitative characters in successive generations in maize inbred lines. Euphytica 22: 172-180.

Saghai-Maroof MA, Soliman KM, Jorgensen RA and Allard RW 1984. Ribosomal DNA spacer-length polymorphisms in barley: Mendelian inheritance, chromosomal location, and population dynamics. Proc. Natl. Acad. Sci. USA 81: 8014-8018.

Satyavathi CT, Tiwari S, Bharadwaj C, Rao AR, Bhat J and Singh SP 2013. Genetic diversity analysis in a novel set of restorer lines of pearl millet [Pennisetum glaucum (L.) R. Br.] using SSR markers. Vegetos 26: $72-82$.

Senior ML, Murthy JP, Goodman MM and Stubber CW 1998. Utility of SSRs for determining genetic similarities and relationships in maize using an agarose gel system. Crop Sci. 38: 1088-1098.

Singh AK, Rana MK, Singh S, Kumar S, Kumar D and Arya L 2013. Assessment of genetic diversity among pearl millet [Pennisetum glaucum (L.) R Br.] cultivars using SSR markers. Range Manag. Agrofor. 34: 77-81.

Singh R, Kharb RPS and Singh V 2003. Genetic divergence study in durum wheat based on seed vigour parameters. Wheat Inform. Service 96: 20-22.

Stich B, Haussmann BIG, Pasam R, Bhosale S, Hash CT, Melchinger AE and Parzies H 2010. Patterns of molecular and phenotypic diversity in pearl millet [Pennisetum glaucum (L.) R. Br.] from West and Central Africa and their relation to geographical and environmental parameters. BMC Plant Biol. 10: 216.

Sumanth M, Sumathi P, Vinodhana NK and Sathya M 2013. Assessment of genetic distance among the inbred lines of pearl millet (Pennisetum glaucum (L.) R. Br.) using SSR markers. Int. J. Biotech. Appl. Flds. 1: 153-162. 